\title{
Labetalol versus Alpha Methyldopa for Control of Pregnancy Induced Hypertension
}

\author{
Shokry E. El-Sadek ${ }^{1, *}$ M.B.B.Ch, Abdalla K. Ahmad ${ }^{1}$ MD, Ahmed M. El-sadek ${ }^{1}$ MD.
}

\author{
* Corresponding Author: \\ Shokry E. El-Sadek \\ dr.sh.pegasus@gmail.com
}

Received for publication May 11, 2021; Accepted June 26, 2021; Published online June 26, 2021.

Copyright The Authors published by Al-Azhar University, Faculty of Medicine, Cairo, Egypt. Users have the right to read, download, copy, distribute, print, search, or link to the full texts of articles under the following conditions: Creative Commons Attribution-Share Alike 4.0 International Public License (CC BY-SA 4.0).

doi: 10.21608/aimj.2021.75967.1473

${ }^{1}$ Obstetrics and Gynecology Department, Faculty of Medicine, Al-Azhar University Cairo, Egypt.

\begin{abstract}
Background: Hypertension is a common medical problematic faced throughout pregnancy and is accompanied with raised risks of opposing consequences.

Aim of the work: to match the effectiveness of labetolol and alpha methyldopa in blood pressure (BP) control in women with Pregnancy Induced Hypertension (PIH).

Patients and methods: This observational study was performed at Department of Obstetrics and Gynecology of AL- HUSSIEN University Hospital and Suez General Hospital after obtaining an approval from institutional board review of Al Azhar University Faculty of Medicine.

Results: A significant change among the studied group in regard to mean drop in SBP and DBP, and Period needed to control BP in labetalol group was significantly lower compared to $\alpha$-Methyldopa group.

Conclusion: Hypertensive diseases throughout gestation are a main reason of morbidity and death all over the world. Antihypertensive drugs have a significant function in treating maternal BP. The current work approves the preceding results that labetalol is an operative and secure medication for usage faster in accomplishing acceptable in controlling of $\mathrm{BP}$ in PIH, in our work we found that Labetalol controls systolic and diastolic Bp more quickly and efficiently than Methyldopa
\end{abstract}

Keywords: Labetalol, Methyldopa, Pregnancy induced hypertension, Antihypertensive.

Disclosure: The authors have no financial interest to declare in relation to the content of this article. The Article Processing Charge was paid for by the authors. Authorship: All authors have a substantial contribution to the article.

\section{INTRODUCTION}

Caesarean section (CS) is one of the most Pregnancy hypertension (High blood pressure (HPB))) is a substantial management issue. Around $12-22 \%$ of all pregnant women are complicated by hypertensive diseases, $70 \%$ of those are influenced by Pregnancy HPB and $30 \%$ by essential HPB ${ }^{1}$.

Pregnancy Hypertensive diseases comprise chronic HPB (ie, HPB detected earlier to 20-wks of pregnancy), pre-eclampsia and eclampsia ${ }^{2}$. chronic HPB with super-imposed preeclampsia (a diagnosing of chronic HPB outside gestation or previous to 20wks' pregnancy and a unexpected aggravation of HPB or appearances of end organ involvements like novel or improved proteinuria, elevated levels of liver enzymes, thrombopenia, pulmonary oedema, renal deficiency, or signs like severe headaches or right higher-quadrant pains), and Pregnancy HPB ${ }^{3}$.

Commonest employed medication for managing PIH are methyldopa, besides $\alpha$ - and $\beta$-blockers, $\beta$ blockers and calcium channel blockers. researches have revealed contradictory fact concerning the foetal and maternal outcome of these medications throughout gestation. Around 6-8\% pregnant women are impacted by PIH internationally ${ }^{4}$.

In the absence of hypertensive crises methyldopa and oral labetalol are preferred drugs. Both these drugs are easily available in our country. Both drugs have been found effective in reducing blood pressure without any adverse effect on perinatal outcome ${ }^{5}$.

Labetalol is a mixed alpha $(\alpha 1)$ and beta $(\beta 1 / \beta 2)$ adrenergic receptor blockers with arteriolar vasodilator impact, consequently decreasing peripheral confrontation and reduces BP. Frequent side effects are headache, drowsiness, and dizziness 6 .

Methyldopa is an agonist of pre-synaptic central nervous system $\alpha 2$ adrenergic receptors resulting in inhibition of sympathetic nervous system thus reducing $\mathrm{BP}$ and it does not affect fetal hemodynamics ${ }^{7}$.

The advantage of labetalol is that it may be given and directed orally and works faster than methyldopa. At present this is well-known that $\beta$-blockers cross the placenta, enters in fetal circulations and can lead to fetal bradycardia. Fact concerning perinatal consequences of labetalol and methyldopa is contentious ${ }^{8}$. 


\section{PATIENTS AND METHODS}

This observational research has been performed at Obstetrics and Gynecology Department of ALHUSSIEN University Hospital and Suez General Hospital after obtaining an approval from IRP of Al Azhar University Faculty of Medicine.

This study was performed on number of 100 -cases with PIH, they have been arbitrarily allocated to either the labetalol or alpha methyldopa, and only the staff had known which of the cases is taking any regimens.

Inclusion criteria: Pregnant females aging from 20 to 40-yrs, Gestational ages between 20 and 37-wks and Females with PIH (BP $\geq 140 \mathrm{mmHg}$ systolic or $\geq 90$ mmHg diastolic or more afterward BP measurements on 2 times with 4-h apart in a formerly ordinary BP.

Exclusion criteria: Pregnant females with essential HBP, previously taking antihypertensive drugs. Fulminant pre-eclampsia (platelet count $<100 \times 10$ or AST >50 IU/liter, persistent signs as headaches, epigastric pains, visual disturbances) and those with eclampsia (general tonic colonic convulsions frequently in accordance to pre-eclampsia). Cases with molar-pregnancy, multi-pregnancy, placentaprevia. Gravid females with renal, hematological or heart disorders.

Operational design: From each patient the following data had been collected upon admission

Initial assessment: Complete full history taking, including: Age, Gender, Address, phone number, occupation, Menstrual history, Previous medical history: substantial disorders, or surgeries, History of DM, History of Other Comorbid Conditions Such as Cardiac disorder, past of $\mathrm{HCV}$ and Special Habits of Medical Importance Like Smoking.

Clinical examination focusing on: General examinations: Essential symptoms (BP, Temp., Respiratory and Heart rates), Weight, Height and BMI. Local examination: Fundal level, Fundal Grip: Pelvic grip

Investigations: Laboratory study: Complete blood picture (CBC): hemoglobin concentration ( $\mathrm{Hb} \%$ ), red blood cells (RBCs), white blood cells (WBCs), platelet count. Renal function testing: blood urea, serum creatinine, and urine analysis. Liver Test Profile: Serum aspartate and alanine aminotransferases (AST and ALT), serum albumin, serum bilirubin, serum gammaglutamyl transferase (GGT), prothrombin time and international normalized ratio (INR).

Imaging:

Ultrasound to assess fetal wellbeing ${ }^{9}$ : This ultrasound scan is usually carried at about 32 weeks of pregnancy.

Fetal Doppler Ultrasound (US) ${ }^{10}$ : Fetal Doppler assessment employs US to count blood flowing speed in the fetal vessels, commonest the umbilical artery. Flowing is more frequently counted via pulsatility or resistant indices. These indices mirror the down-stream vascular resistances by counting the variances among the peak systolic and the enddiastolic speed in blood vessels of interesting in every cardiac cycle.

Procedures:

Each participant had been undergone the following measures related to this research: Measuring baseline $\mathrm{BP}$ using standard mercury sphygmomanometer ${ }^{11}$ : Seat the case for 5 to 10 -mins previous to $\mathrm{BP}$ measurements. In semi sitting or left side location, Cuff size suitable to the case`s arm circumference and located 20-30 $\mathrm{mm}$ over the antecubital fossa., Locating of the central part of the rubber bladder on the brachial artery and Locating of the higher limb at the heart height. Steady following-up in the antenatal clinic in routine visits where cases were screened in the antenatal clinic afterward 2-dayes from receiving the medication. Dosage had been evaluated to control BP when there was no drop in BP even afterward 2-dayes of receiving medication, medication dosage has been doubled. Then screened in the antenatal clinic every week for 2-wks. Then every 2-wks until born. Drop in mean arterial BP with labetalol/methyldopa, Period needed for BP control, Average medication dosages needed for BP controlling and Side effects of medications were recorded. Ultrasound and Doppler study every 2 weeks.

Statistical Analysis: Collected data analysis were performed via windows-based IBM-SPSS. Data were evaluated for normal distributions via the Shapiro Walk testing. Qualitative data have been introduced in the form of frequency and percent. Chi square testing $\left(\chi^{2}\right)$ and Fisher exact was employed to compute change among qualitative variables as showed. Quantitative data have been introduced in the form of mean \pm SD (Standard deviation) for parametric and median and ranges for non-parametric data. All statistical evaluations were dual tailed with significancy Levels at P-value $\leq 0.05$ was considered significant, $p<0.001$ was considered high significant change while, P> 0.05 was considered Nonsignificant change.

\section{RESULTS}

Mean \pm SD of age in labetalol group is31.7 \pm 4.9 , and was $33.1 \pm 4.12$ in $\alpha$-Methyldopa groups, there are nonsignificant differences between the groups regarding age, BMI, and gravida. Table1. 


\begin{tabular}{|c|c|c|c|c|c|}
\hline & & $\begin{array}{c}\text { Labetalol } \\
(n=50)\end{array}$ & $\begin{array}{c}\boldsymbol{\alpha} \text {-Methyldopa } \\
(n=50)\end{array}$ & $t / Z^{2}$ & $p$ \\
\hline \multicolumn{2}{|c|}{$\begin{array}{l}\text { Age (years) } \\
\text { Mean } \pm S D\end{array}$} & $31.7 \pm 4.91$ & $33.1 \pm 4.12$ & 1.54 & .126 \\
\hline \multicolumn{2}{|c|}{$20-25$ years } & 25 (50\%) & 24 (48\%) & \multirow{3}{*}{.709} & \multirow{3}{*}{.701} \\
\hline \multicolumn{2}{|c|}{$26-30$ years } & $23(46 \%)$ & $22(44 \%)$ & & \\
\hline \multicolumn{2}{|c|}{$>30$ years } & $2(4 \%)$ & $4(8 \%)$ & & \\
\hline \multicolumn{2}{|c|}{$\begin{array}{c}\text { BMI }\left(\mathrm{kg} / \mathrm{m}^{2}\right) \\
\text { Mean } \pm S D\end{array}$} & $29.42 \pm 3.39$ & $30.60 \pm 2.84$ & 1.89 & .062 \\
\hline \multirow{2}{*}{ Gravida } & Primigravida & 34 (68\%) & 28 (56\%) & \multirow{2}{*}{1.53} & \multirow{2}{*}{.217} \\
\hline & Multigravida & $16(32 \%)$ & $22(44 \%)$ & & \\
\hline
\end{tabular}

Table 1: Demographic characteristics between the two groups

In labetalol group; $24 \%$ had SBP $<150 \mathrm{mmHg}, 76 \%$ had SBP $>150 \mathrm{mmHg}$, DBP was $<100 \mathrm{mmHg}$ in $30 \%$, and $>100 \mathrm{mmHg}$ in $70 \%$, in $\alpha$-Methyldopa group; $20 \%$ had SBP $<150 \mathrm{mmHg}, 80 \%$ had SBP $>150 \mathrm{mmHg}$, DBP was $<100 \mathrm{mmHg}$ in $26 \%$, and $>100 \mathrm{mmHg}$ in $74 \%$, there was nonsignificant difference between groups as regard BP before treatment. Table2.

\begin{tabular}{|c|c|c|c|c|c|}
\hline & & $\begin{array}{l}\text { Labetalol } \\
(n=50)\end{array}$ & $\begin{array}{l}\alpha \text {-Methyldopa } \\
(n=50)\end{array}$ & $\mathbb{Z}^{2}$ & $\boldsymbol{P}$ \\
\hline \multirow{2}{*}{$S B P$} & $<150 \mathrm{mmHg}$ & 12 (24\%) & $10(20 \%)$ & \multirow{2}{*}{.233} & \multirow{2}{*}{.629} \\
\hline & $>150 \mathrm{mmHg}$ & 38 (76\%) & 40 (80\%) & & \\
\hline \multirow{2}{*}{$D B P$} & $<100 \mathrm{mmHg}$ & 15 (30\%) & $13(26 \%)$ & \multirow{2}{*}{.198} & \multirow{2}{*}{$.65 €$} \\
\hline & $>100 \mathrm{mmHg}$ & 35 (70\%) & 37 (74\%) & & \\
\hline
\end{tabular}

Table 2: BP distribution before treatment between the two groups

A significant change was found among the studied group in regard to mean drop in SBP and DBP. Table 3.

\begin{tabular}{|l|l|l|l|l||}
\hline & $\begin{array}{l}\text { Labetalol } \\
(n=50)\end{array}$ & $\begin{array}{l}\boldsymbol{\alpha} \text {-Methyldopa } \\
(n=50)\end{array}$ & MU & $\boldsymbol{p}$ \\
\hline $\begin{array}{l}\text { SBP }(\mathrm{mmHg}) \\
\text { Mean } \pm S D\end{array}$ & $5.88 \pm 2.01$ & $3.22 \pm 1.15$ & 4.23 \\
\hline $\begin{array}{l}\text { DBP }(\mathrm{mmHg}) \\
\text { Mean } \pm S D\end{array}$ & $7.05 \pm 2.91$ & $4.18 \pm 2.19$ & 5.17 & .000 \\
\hline
\end{tabular}

Table 3: Mean drop in blood pressure after 48 hours of treatment between the two groups

Time needed for BP controlling in labetalol group was significantly lower in comparison to $\alpha$-Methyldopa group.

Table (4)

\begin{tabular}{|l|l|l|l|}
\hline & $\begin{array}{l}\text { Labetalol } \\
(n=50)\end{array}$ & $\begin{array}{l}\boldsymbol{\alpha}-\text { Methyldopa } \\
(n=50)\end{array}$ \\
\hline $\begin{array}{l}\text { Time (day) } \\
\text { Mean } \pm S D\end{array}$ & $3.32 \pm 1.65$ & $4.11 \pm 1.94$ \\
\hline
\end{tabular}

Table 4: Time required controlling blood pressure between the two groups

A significant change among the study groups regarding GA. Table (5) 


\begin{tabular}{|l|l|l|l|l|}
\hline & $\begin{array}{l}\text { Labetalol } \\
(n=50)\end{array}$ & $\begin{array}{l}\boldsymbol{\alpha} \text {-Methyldopa } \\
(n=50)\end{array}$ & $t$ & $\boldsymbol{p}$ \\
\hline $\begin{array}{l}\text { GA (weeks) } \\
\text { Mean } \pm S D\end{array}$ & $37.29 \pm 0.808$ & $37.8 \pm 0.629$ & 3.52 & $\mathbf{. 0 0 1}$ \\
\hline $\begin{array}{l}\text { Birth weight }(\mathrm{kg}) \\
\text { Mean } \pm \text { SD }\end{array}$ & $2.98 \pm 0.338$ & $2.97 \pm 0.134$ & .194 & .846 \\
\hline $\begin{array}{l}\text { Apgar at 1 } \text { min } \\
\text { Mean } \pm S D\end{array}$ & $7 \pm 1.54$ & $6.89 \pm 2.26$ & .284 & .777 \\
\hline $\begin{array}{l}\text { Apgar at } 5 \text { min } \\
\text { Mean } \pm S D\end{array}$ & $9.82 \pm 1.28$ & $9.71 \pm 1.49$ & .396 & .693 \\
\hline
\end{tabular}

Table 5: Neonatal outcomes between the two groups

\section{DISCUSSION}

Hypertension (High Blood Pressure (HBP)) is the commonest medical problematic faced throughout gestation. HBP complicates up to $10 \%$ of all gestations and is accompanied with improved risk of opposing fetal, neonatal and motherly consequences, involving preterm birth, diabetes, chronic HBP, perinatal mortality, acute renal or hepatic failures, antepartum hemorrhage, postpartum hemorrhage and maternal mortality ${ }^{12}$.

This was a comparative observational research that was demonstrated at Department of Obstetrics and Gynecology of AL- HUSSIEN University Hospital and Suez General Hospital after obtaining an approval from institutional board review of Al Azhar University Faculty of Medicine, the study was performed on number of 100 cases with $\mathrm{PIH}$, they had been randomly assigned to either the labetalol or alpha methyldopa, and only the staff had known which of the patients is taking either regimen.

Analysis of our findings revealed that the Mean \pm SD of age in labetalol group is $31.7 \pm 4.9$, and was $33.1 \pm$ 4.12in $\alpha$-Methyldopa groups, there are nonsignificant differences between the groups regarding age, BMI, and gravida.

In agreement with our findings, the study of Subhedar et al., ${ }^{13}$ reported that between the entire number 18-cases, highest number of cases (92-cases) was in ages ranging between 15 and 24-yrs: 48-cases (53.33\%) in Group-A and 44-cases (48.89\%) in Group-B. The ages mean of the cases in Group-A was 24.41-yrs and in group-B was 24.85-yrs. The ages mean was nonsignificant in the two groups, 102 -cases were primigravidae, 53 -cases $(58.89 \%)$ in methyldopa group and 49-cases (54.44\%) in labetalol group. The change among the studied groups was non-significant.

In another study of Gurjar and Malewar, ${ }^{12}$ reported that Methyldopa group, there were 52 (52\%) patients in the age range of 21-25 years, while in Labetalol group, and there were 51 (51\%) cases. There were 47 (47\%) cases from Methyldopa group in the age range of 26 - 30 years, while 45 in the Labetalol group.
In the present study, we reported that in labetalolgroup; $24 \%$ had SBP $<150 \mathrm{mmHg}, 76 \%$ had SBP $>150 \mathrm{mmHg}$, DBP was $<100 \mathrm{mmHg}$ in $30 \%$, and $>100 \mathrm{mmHg}$ in $70 \%$, in $\alpha$-Methyldopa group; $20 \%$ had SBP $<150 \mathrm{mmHg}, 80 \%$ had SBP $>150 \mathrm{mmHg}$, DBP was $<100 \mathrm{mmHg}$ in $26 \%$, and $>100 \mathrm{mmHg}$ in $74 \%$, there was nonsignificant change among study groups regarding BP before management.

In Accordance to a report made by Abalos et al., ${ }^{14}$ the average MAP in the studied groups was identical earlier to management. A high significant drop in MAP in the labetalol-group (p0.05).

In alike report by El Qarmalawi et al., ${ }^{15} 81.4 \%$ of cases in labetalol-group had a significant drop in MAP in comparison to $68.5 \%$ in methyldopa-cases.

In the Subhedar et al., ${ }^{13}$ report, the mean arterial pressure of cases received methyldopa on admission was $109.86-\mathrm{mmHg}$, whereas on $7^{\text {th }}$ day decreased to 98.15-mmHg, with a statistical significance, with labetalol; the mean arterial pressure on admission was 109.48-mmHg and decreased to $96.90-\mathrm{mmHg}$ on $7^{\text {th }}$ day. Decrease in MAP has statistical significance. On comparison the 2 medications, MAP on admission were similar but on $7^{\text {th }}$-day, significant reduction in MAP was found in labetalol-group.

In the study of Pentareddy et al., ${ }^{3}$ revealed that mean systolic BP was $123.66 \pm 10.332$ in Methyldopa-cases and 121.66 \pm 7.4664 in Labetalol-cases at the time of delivery. 2 patients in methyldopa-cases and 1 patient in labetalol group had severe hypertension.

It is in accordance with the study conducted by Cruikshank et al., ${ }^{16}$ which observed that Labetalol had rapid control of BP in 88\% of patients. Additional report by Lardoux's et al., 1983 also revealed fast drop in BP in $82 \%$ of Labetalol-cases while it was found in 92\% Labetalol-cases in report by Michael et al., ${ }^{17}$.

Pentareddy et al., ${ }^{3}$ concluded that methyldopa decreased BP from mean diastolic BP $94.00 \pm 4.98$ to $82.00 \pm 5.61 \mathrm{mmHg}$. There was significant reduction in BP before and after treatment ( $p$ value $<0.001$ ), Labetalol reduced Mean diastolic BP of $96.67 \pm 4.79$ to $79.00 \pm 5.53$, with labetalol, also a significant decrease of BP before and afterward management (p value $<0.001$ ), On comparison between methyldopa 
and labetalol groups, change in drop in mean DBP was nonsignificant ( $p$ value $>0.005$ )

Labetalol is an operative anti-hypertensive that reduces systolic in addition to diastolic BP in $\mathrm{PIH}$ was confirmed previously, in Dharwadkar et al., ${ }^{18}$ around $55 \%$ of the methyldopa -cases receiving nifedepine and phenobarbitone but only $22.5 \%$ of labetalol-cases receiving injections labetalol and phenobarbitone giving that methyl dopa needs extra medications BP managements than labetalol. The present work revealed that labetalol is more good medication in well dropping the BP of the cases and then preserve optimum BP level.

Furthermore, in the current study, we found that period needed for BP controlling in labetalol cases was significantly lower compared to $\alpha$-Methyldopa group.

This is in accordance to the study of Subhedar et al., ${ }^{13}$ which concluded that the mean period needed for $\mathrm{BP}$ controlling in group-A was 42.22-h and in group$B$ it was 36.97-h. The variance among the studied groups was significant with labetalol display former controlling of BP in comparison to methyldopa.

The report of Alalfy et al., ${ }^{19}$,revealed a decrease in the mean arterial BP starting from a baseline that was the $\mathrm{BP}$ before receiving of the anti-hypertensive therapy and the records afterward 2-dayes, 1, 3, 5, 7, 9-wks afterward medication receiving and at born time in the methyldopa and labetalol cases, a significant change in BP controlling with levels of systolic, diastolic and mean arterial BP records are lesser in labetalol cases in comparison to methyldopa cases afterward 2-dayes, 1, 3, 5, 7, 9-wks post medication treatment and at born time with $\mathrm{P}<0.001$ showing more good BP control.

In the current study, as regard neonatal outcomes, a significant change was found among the study groups regarding GA, with non- statistical significant differences as regard mass of birth, Apgar at 1-min, and Apgar at 5-min.

Subhedar et al., ${ }^{13}$ reported that 9-cases in group A (33.33\%) went in non-induced delivery while 18cases $(66.67 \%)$ were induced. In group-B, 23-cases (48.94\%) went in non-induced delivery and 24-cases (51.06\%) were induced. It was found that these values have statistical significance, thus the noninduced delivery rate was more in labetalol-cases. This can be reported to the fact that labetalol has maturing impact on the cervix.

The findings of El-Qarmalawi et al., ${ }^{15}$ propose higher occurrence of non-induced onset of labor in the labetalol cases, Lamming et al., ${ }^{20}$ also revealed a higher occurrence of non-induced labor in the labetalol cases.

Easterling et al., ${ }^{8}$ reported that delivery outcome didn't differ among groups. About two-thirds of females in every group delivered via caesarean section (190 [64\%] of 295 cases in the nifedipinegroup; 186 [64\%] of 290 -females in the labetalol cases; and 179 [61\%] of 295 females in the methyldopa cases), predominantly as of unsuccessful inductions of delivery and fetal heart rate irregularities the median time from registration to labour was about one day, The occurrence of stillbirth, neonatal mortality, and neonatal morbidity didn't differ among groups. But, the frequency of neonatal admissions to intensive care unit (ICU) was significantly high in babies of mothers allocated to nifedipine vs. labetalol $(p=0 \cdot 009)$ and methyldopa $(\mathrm{p}=0 \cdot 004)$, predominantly owing to low or very low weights of birth. The mean periods of stay in ICU (lesser than vs at minimum 1-day) didn't vary among groups.

\section{CONCLUSION}

Hypertensive diseases throughout gestation are a main reason of morbidity and death all over the world. Anti-hypertensive drugs have a significant function in maternal BP management. the current work approves the preceding results that labetalol is an operative and secure medication for usage faster in accomplishing suitable in the BP controlling in $\mathrm{PIH}$, in our work we found that Labetalol controls systolic and diastolic BP more quickly and efficiently than Methyldopa.

\section{REFERENCES}

1. Tanz LJ, Stuart JJ, Missmer SA. Cardiovascular biomarkers in the years following pregnancies complicated by hypertensive disorders or delivered preterm. Pregnancy hypertension 2018; 13, 14-21.

2. Brown MA, Magee LA, Kenny LC. Hypertensive disorders of pregnancy: ISSHP classification, diagnosis, and management recommendations for international practice. Hypertension. 2018; 72(1), 2443.

3. Pentareddy MR, Shailendra D, Prasuna G. Safety and efficacy of methyldopa and labetalol in controlling blood pressure in hypertensive disorders of pregnancy. International Journal of Basic \& Clinical Pharmacology. 2017; 6(4), 942.

4. Kalsoom S, Majeed N, Riaz M. Labetalol Versus Methyldopa: Comparison of Frequency of Small for Gestational Age in the Treatment of Pregnancy Induced Hypertension. Journal of Rawalpindi Medical College. 2018; 346-9.

5. Akhtar N, Hayat Z and Nazim F. Comparison betwen labetalol and methyldopa in the treatemnt of preeclampsia. Journal of Postgraduate Medical Institute (Peshawar-Pakistan) .2018; 32(1), 35-9.

6. Lin $\mathrm{Y}$, Zhang $\mathrm{Y}$, Jiang $\mathrm{YN}$. Medication for management of pregnancy-induced hypertension. Clinical Trials in Degenerative Diseases. 2018; 3(2), 83.

7. Xu B, Bobek G, Makris A. Antihypertensive methyldopa, labetalol, hydralazine, and clonidine reversed tumour necrosis factor- $\alpha$ inhibited endothelial nitric oxide synthase expression in endothelial-trophoblast cellular networks. Clinical and Experimental Pharmacology and Physiology. 2017; 44(3), 421-7. 
8. Easterling $\mathrm{T}$, Mundle $\mathrm{S}$, Bracken $\mathrm{H}$. Oral antihypertensive regimens (nifedipine retard, labetalol, and methyldopa) for management of severe hypertension in pregnancy: an open-label,randomised controlled trial. The Lancet. 2019; 394(10203), 101121.

9. Salomon L. J., Alfirevic Z., Da Silva Costa F., Deter R. L., Figueras F., Ghi, Tet al. ISUOG Practice Guidelines: ultrasound assessment of fetal biometry and growth. Ultrasound in Obstetrics \& Gynecology. 2019; 53(6), 715-23.

10. Jezewski J., Wrobel J., Matonia A., Horoba K., Martinek R., Kupka T., et al. Is abdominal fetal electrocardiography an alternative to doppler ultrasound for FHR variability evaluation. Frontiers in physiology. 2017; 8, 305.

11. Ngene, N. C., \& Moodley, J. Baseline check of blood pressure readings of an automated device in severe pre-eclampsia and healthy normotensive pregnancy. Pregnancy hypertension.2018; 12, 47-52.

12. Gurjar BG, Malewar SS. Study of labetalol vs. methyldopa in treatment of pregnancy induced hypertension. Int $J$ Reprod Contracept Obstet Gynecol. 2019; 8:2378-83.

13. Subhedar V, Inamdar $S$, Hariharan $C$, Subhedar S Comparison of efficacy of labetalol and methyldopa in patients with pregnancy-induced hypertension. Int J Reprod Contracept Obstet Gynecol. 2013; 2:27-34.
14. Abalos, E., Duley, L., Steyn, D. W., \& Gialdini, C. Antihypertensive drug therapy for mild to moderate hypertension during pregnancy. Cochrane database of systematic reviews. 2018; (10).

15. El-Qarmalawi AM, Morsy AH, al-Fadly A, Obeid A, Hashem M. Labetalol vs. methyldopa in the treatment of pregnancy-induced hypertension. Int $J$ Gynaecol Obstet. 1995; 49:125-30.

16. Cruickshank DJ, Robertson AA, Campbell DM, MacGillivray I. Does Labetalol influence the development of proteinuria in pregnancy hypertension? A randomised controlled study. Eur J Obstet Gynecol Reprod Bio. 1992; 45:47-51.

17. Michael CA. Use of Labetalol in the treatment of severe hypertension during pregnancy. $\mathrm{Br} J$ Clin Pharmacol. 1979; 8:211S-5S.

18. Dharwadkar MN, Kanakamma MK, Dharwadkar SN, Rajagopal K, Gopakumar C. Study of Methyl Dopa Versus Labetalol in Management of Preeclampsia and Gestational Hypertension. Gynecol Obstet (Sunnyvale). 2014; 4: 242 doi:10.4172/21610932.1000242.

19. Alalfy M, E.Eltaieb, Mahmoud.Soliman. Labetalol in Comparison to Methyl Dopa in Treatment of Gestational Hypertension, A Randomized Trial. J Gynecol Res. 2018; 4(1): 101.

20. Lamming GD \& Symonds EM. Use of Labetalol and Methyldopa in Pregnancy-Induced Hypertension. $\mathrm{Br}$ J Clin Pharmacol. 1979; 8:217S22S 